\title{
Correction to: Integrating cross-sensor high spatial resolution satellite images to detect subtle forest vegetation change in the Purple Mountains, a national scenic spot in Nanjing, China
}

\author{
Fangyan Zhu ${ }^{1} \cdot$ Wenjuan Shen ${ }^{1} \cdot J^{\prime a o j i a o ~ D i a o}{ }^{1} \cdot$ Mingshi Li ${ }^{1,2} \cdot$ Guang Zheng $^{3}$
}

Published online: 11 June 2019

(C) The Author(s) 2019

Correction to: J. For. Res. https://doi.org/10.1007/s11676-019-00978-x

The article "Integrating cross-sensor high spatial resolution satellite images to detect subtle forest vegetation change in the Purple Mountains, a national scenic spot in Nanjing, China”, written by Fangyan Zhu, Wenjuan Shen, Jiaojiao Diao, Mingshi Li and Guang Zheng, was originally published electronically on the publisher's Internet portal (currently SpringerLink) on 14 May 2019 without open access.

With the author(s)' decision to opt for Open Choice, the copyright of the article will be changed on 15 June 2019 to

(C) The Author(s) 2019 and the article is forthwith distributed under the terms of the Creative Commons Attribution 4.0 International License (http://creativecommons. org/licenses/by/4.0/), which permits use, duplication, adaptation, distribution and reproduction in any medium or format, as long as you give appropriate credit to the original author(s) and the source, provide a link to the Creative Commons license and indicate if changes were made. The original article has been corrected.

Publisher's Note Springer Nature remains neutral with regard to jurisdictional claims in published maps and institutional affiliations.

The original article can be found online

at https://doi.org/10.1007/s11676-019-00978-x.

Mingshi Li

nfulms@njfu.edu.cn

1 College of Forestry, Nanjing Forestry University, Nanjing 210037, People's Republic of China

2 Co-Innovation Center for Sustainable Forestry in Southern China, Nanjing Forestry University, Nanjing 210037, People's Republic of China

3 Jiangsu Provincial Key Laboratory of Geographic Information Science and Technology, International Institute for Earth System Science, Nanjing University, Nanjing 210023, People's Republic of China 